\title{
Discontinuity survey and brittle fracture characterisation in open pit slopes using photogrammetry
}

\author{
Z Tuckey SRK Consulting (Australasia) Pty Ltd, Australia \\ J Paul SRK Consulting (Australasia) Pty Ltd, Australia \\ J Price SRK Consulting (Australasia) Pty Ltd, Australia
}

\begin{abstract}
Remote sensing techniques, such as ground-based photogrammetry and LiDAR, have become routine supplements to traditional rock mass characterisation approaches, greatly enhancing discontinuity survey capability. Concurrently, discrete fracture network simulations, constructed using field discontinuity mapping and borehole logging data, are increasingly being applied to advanced numerical modelling studies of rock slope stability, leading to improved understanding of progressive slope failure involving brittle fracture initiation, propagation, and coalescence. Despite continuing technological advances, predictive modelling of rock slope stability is still limited by our inability to observe the hidden interior structure of a rock mass, and by computational limitations restricting the explicit simulation of small scale material heterogeneity and localisation phenomena inherent to brittle fracture.

This paper presents discontinuity mapping observations from a photogrammetry investigation of an Australian open pit mine, with emphasis on the influence of survey scale and resolution on discontinuity characterisation. We also discuss the application of fractography principles to interpretation of brittle rock mass damage, focussing on characterisation of irregular brittle fractures induced by blasting, and on incipient discontinuities which retain cohesion and tensile strength from intact rock bridges. Based on the results, we make recommendations for improving photogrammetry-based discontinuity mapping procedures in order to improve collection of both quantitative data on discontinuity persistence and intensity, and also qualitative characterisation of rock mass damage in open pit slopes.
\end{abstract}

\section{Introduction}

Ground based digital photogrammetry has become a popular addition to the geotechnical toolbox for open pit slope stability assessment, allowing for detailed mapping of rock discontinuities in steep or unsafe areas that are inaccessible for conventional window or scanline mapping (Sturzenegger \& Stead 2009). The resolution of photogrammetry models is limited only by computer RAM, and the camera image sensor and lens configuration; current high-end DSLR cameras, combined with long focal length telephoto lenses, can produce 3D rock slope models with resolution and point accuracy in the order of a few centimetres from distances up to $2 \mathrm{~km}$ (Wolter 2014). Despite the potential for photogrammetry to produce highly detailed 3D models, in open pit mining practice, most models are not examined in exhaustive detail.

Photogrammetry mapping investigations of open pit slopes usually focus on planar discontinuities, with persistence typically greater than two metres. During data processing, circular discs are fitted to the discontinuities and the resulting dataset includes coordinates of discontinuity centres, orientations, and disc diameters, which are used as a proxy measure of discontinuity persistence. Some investigations may also include measurements of discontinuity spacing, collected by measuring the orthogonal distance between joints belonging to the same structural set (Lato et al. 2012; Fekete et al. 2010). Although increasing research has been applied to automated detection of block edges and discontinuity traces (for example, with 2D photographs by Hadjigeorgiou et al. (2003); and with 3D LiDAR and photogrammetry models by Lato \& Vöge (2012)), manual mapping is still more common, largely because (1) automatically detected features still 
require review by a qualified engineer or geologist to check for accuracy; and (2) automated detection methods tend to underestimate the degree of fracturing in the rock mass (Lemy \& Hadjigeorgiou 2003).

As with any discontinuity mapping technique, the quality of discontinuity spacing, persistence, and intensity data is strongly influenced by sampling bias and error dependent on outcrop orientation (Terzaghi 1965; Baecher \& Lanney 1978), occlusion (Lato et al. 2009), survey scale (Ortega et al. 2006) and model resolution (Sturzenegger \& Stead 2009). Optimal data collection requires mapping of multiple exposures with different orientations, and is easier to carry out in blocky rock masses with moderate to high relief. Discontinuity measurements in poor quality rock masses with intense fracturing can require close range mapping at the centimetre to metre scale and, consequently, highly fractured rock is frequently under-sampled or omitted from conventional mapping investigations. Undulating discontinuities may be oversimplified as planar discs, and irregular brittle fractures with low persistence, induced by blasting or progressive failure of intact rock, are rarely included in the structural measurements.

We suggest that conventional digital mapping approaches do not take full advantage of the 3D rock mass characterisation potential of photogrammetry. We discuss results from a photogrammetry investigation of an Australian open pit mine, with focus on the evidence of brittle fracture and other key parameters that are relevant (but frequently ignored) in fracture-mechanics based simulation of progressive slope failure:

- Fracture intensity: areal intensity of discontinuities $\left(P_{21}\right.$ with units of $\left.\mathrm{m}^{-1}\right)$ is calculated as the total trace length of discontinuity traces in a window map, divided by the surface area of the window. $\mathrm{P}_{21}$ is a key input for the construction and calibration of discrete fracture network (DFN) models (Elmo et al. 2014) and synthetic rock mass (SRM) simulations (Mas Ivars et al. 2011).

- Fracture terminations and incipient joints: termination style describes whether discontinuities terminate in intact rock, or against other pre-existing discontinuities; the proportion of joints terminating in intact rock can be used to assess the content of intact rock bridges (Priest 1993) and to understand the state of development of incipient joints (Hencher 2015), which have not yet coalesced into persistent mechanical interfaces.

- Non-planar discontinuities: undulating faults and folds can have significant impacts on the kinematics of slope instability (Wolter et al. 2014) and on the distribution and intensity of tectonic rock mass damage (Stead \& Wolter 2015; Brideau et al. 2009); we discuss the use of photogrammetry to characterise the waviness (first order roughness; Patton 1966) of major undulating discontinuities.

- Blasting induced damage: blasting damage degrades intact rock via initiation and propagation of microcracks near the blast holes, and also by extension and dilation of pre-existing discontinuities further inside the rock mass (Etchells et al. 2013); we investigate the application of photogrammetry to characterise the severity of blast damage in bench faces, introducing an analogue intensity parameter $B_{21}$ that is calculated as the total length of blasting fracture traces divided by the surface area of a digital bench face window map.

Based on the results of the field investigation, we discuss opportunities to improve photogrammetry data collection for brittle fracture characterisation in open pit slopes, with the aim of optimising data collection for fracture-mechanics based studies of progressive open pit slope instability.

\section{$2 \quad$ Background}

\subsection{Progressive slope failure and brittle fracture}

The concept of progressive slope instability was introduced by Bjerrum (1967), who investigated progressive failure of overconsolidated clay slopes and showed that global instability is preceded by the progressive development of a sliding surface, along which shear strength is locally reduced to residual values. Later research into instability of fractured rock slopes has supported the same concept: failure frequently involves progressive development of rock mass damage, characterised by the fracturing of intact rock bridges and the 
destruction of asperities along pre-existing discontinuities, culminating in the formation of a through-going failure surface (Stead \& Eberhardt 2013). Recent research has emphasised the importance of rock tensile strength in particular for slope failure mechanisms involving progressive brittle fracture (Alzo'ubi 2009).

Brittle fracture of intact rock is a localisation phenomenon, driven by crack initiation and propagation at localised zones of stress concentration near the tips of pre-existing discontinuities, mineral grain boundaries, or even microscopic intracrystalline imperfections (Eberhardt 1998). Rock joints are typically characterised as mode I tensile fractures (Mandl 2005; Gudmundsson 2011); however, brittle fractures produced during blasting and gravity-driven slope failure and secondary fractures around the margins of joints, such as en echelon cracks and hackle fringes (Figure 1), may form under mixed mode conditions (Bahat et al. 2005).

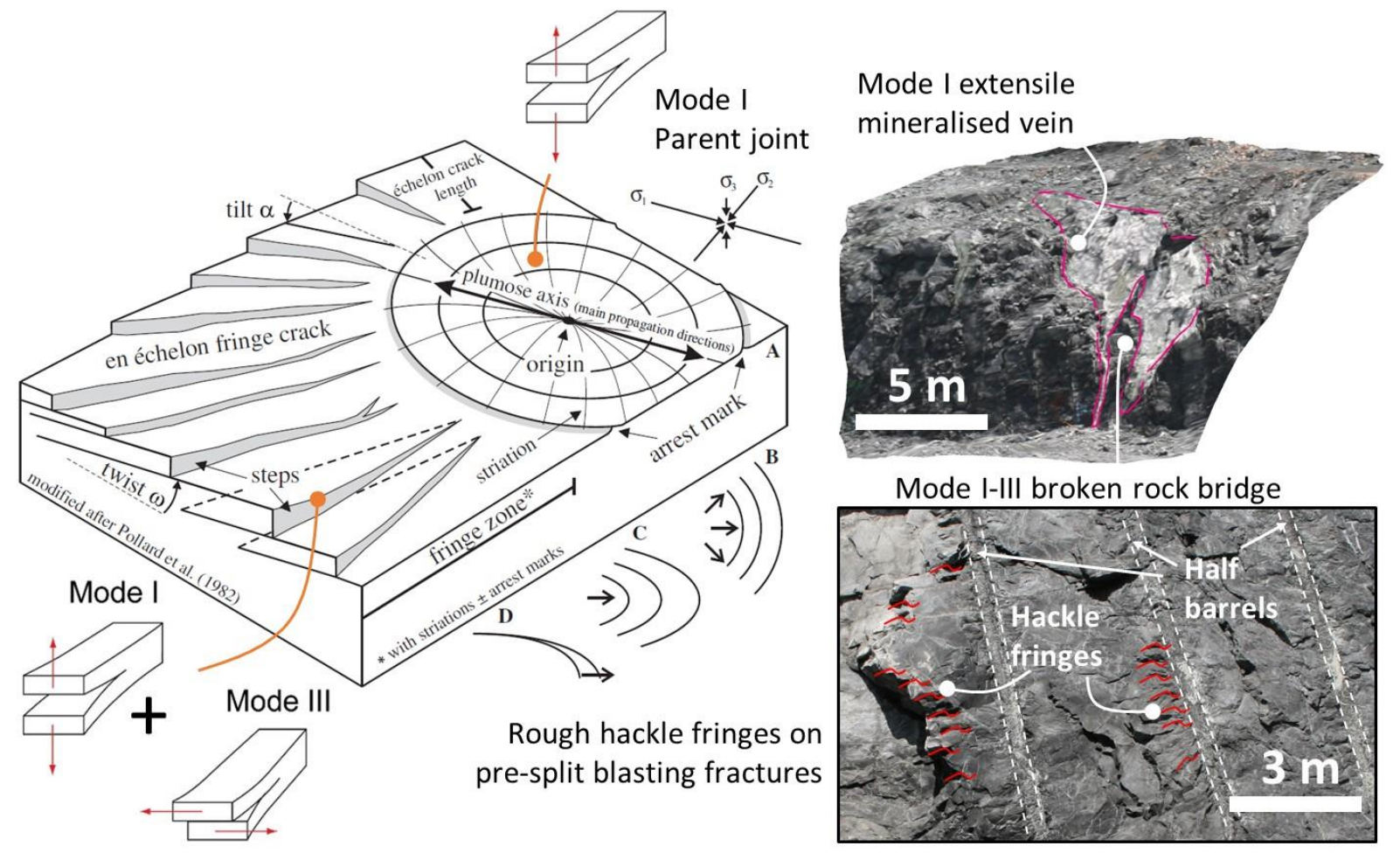

Figure 1 Conceptual application of fractography mapping (modified after Ziegler 2014)

Fractography is the study of fracture surface morphology, and it can reveal details about the fracture formation conditions, notably (1) the stress conditions at the time of fracture; and (2) the speed of fracture propagation, whether slow and stable (attributed to many geological processes), or fast and unstable (attributed to blasting damage). Many experimental fractography studies have been undertaken using metals, glass, and plastics; however, rock fractography is less established (Ameen 1995). We suggest that basic field scale fractography interpretation may provide useful insight into fracture formation conditions in open pit slopes and the role of tensile cracking in rock mass behaviour. Figure 1 illustrates a conceptual diagram of fractography markings on sheet joints in granite by Ziegler (2014), and conceptual interpretation of two fractures from the current study site: one extensile (mode I) mineralised vein, with a rock bridge broken by blasting, and a tensile, pre-split blasting induced fracture with rough hackle fringes indicating rapid loading and unstable fracture propagation.

\subsection{Incipient joints and rock bridges}

Intact rock, although free of visible discontinuities, can contain a fabric of microcracks produced by stress changes from geological processes including magmatic flow direction and cooling in igneous rocks, tectonic action, and glaciation. Microcrack fabric can produce preferential splitting directions in intact rock, such as the orthogonal rift, grain, and hardway axes exploited in granite quarries (Almeida et al. 2006). Over time, 
the fabric of microcracks can become denser, and individual cracks may propagate and coalesce to form persistent mechanical discontinuity interfaces (Hencher \& Knipe 2007).

Hencher (2014) proposed that incipient discontinuities could be categorised according to their tensile strength relative to the parent intact rock; Shang et al. (2015) reported results from laboratory direct tension tests on incipient bedding planes and joints, showing that incipient bedding planes could retain between 32 and $88 \%$ of intact rock tensile strength, and incipient joints could retain between 23 and $64 \%$ of intact rock tensile strength.

We recorded evidence of incipient joints wherever intermittent, coplanar trace patterns coincided with joint terminations in intact rock, identifying several apparently incipient joint sets likely retaining cohesion and tensile strength from intact rock bridges. In these incipient joint sets, the full apparent trace length mapped using 3D polyline features can be compared with the diameter of the visible open discontinuity segments mapped as 3D discs; the results intuitively demonstrate that the apparent persistence of the open discontinuity segments can be much shorter than the length of complete inferred trace lines (Figure 2).

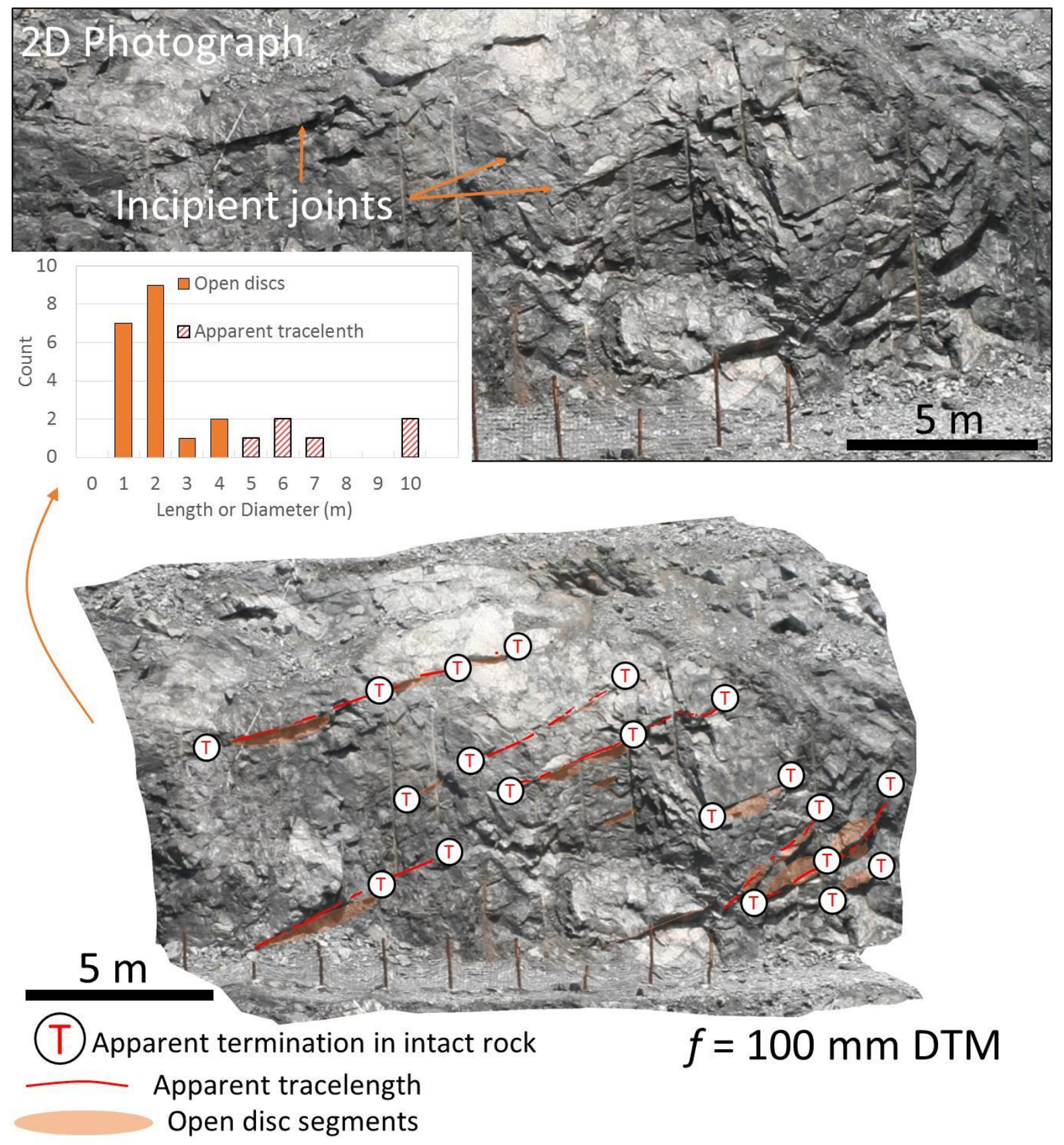

Figure 2 Incipient joints with termination in intact rock at the current study site 


\subsection{Blasting damage}

Blasting degrades the cohesion and tensile strength of intact rock near pre-existing discontinuities, and also creates new brittle fractures that can provide kinematic release for bench-scale failures (Hagan et al. 1978). In practice, blast damage is generally considered to be confined to a shallow zone behind the pit walls, extending in the order of 0.5 to 2.5 times the bench height behind the face, depending on use of controlled blasting techniques such as buffer and pre-split blasting (Hoek \& Karzulovic 2000).

We identified blasting damage in our photogrammetry models using circular discs for incipient discontinuities broken open by blasting, and irregular polylines for low persistence, irregular tensile fractures (Figure 3). The intensity of irregular blasting induced fractures in 3D bench window maps can be expressed using an intensity parameter $B_{21}$ analogous to the intensity of pre-existing discontinuities $P_{21}$, calculated as the total length of fracture traces divided by the mapping window surface area.

\section{Mostly tensile pre-split blasting fractures near bench crest}

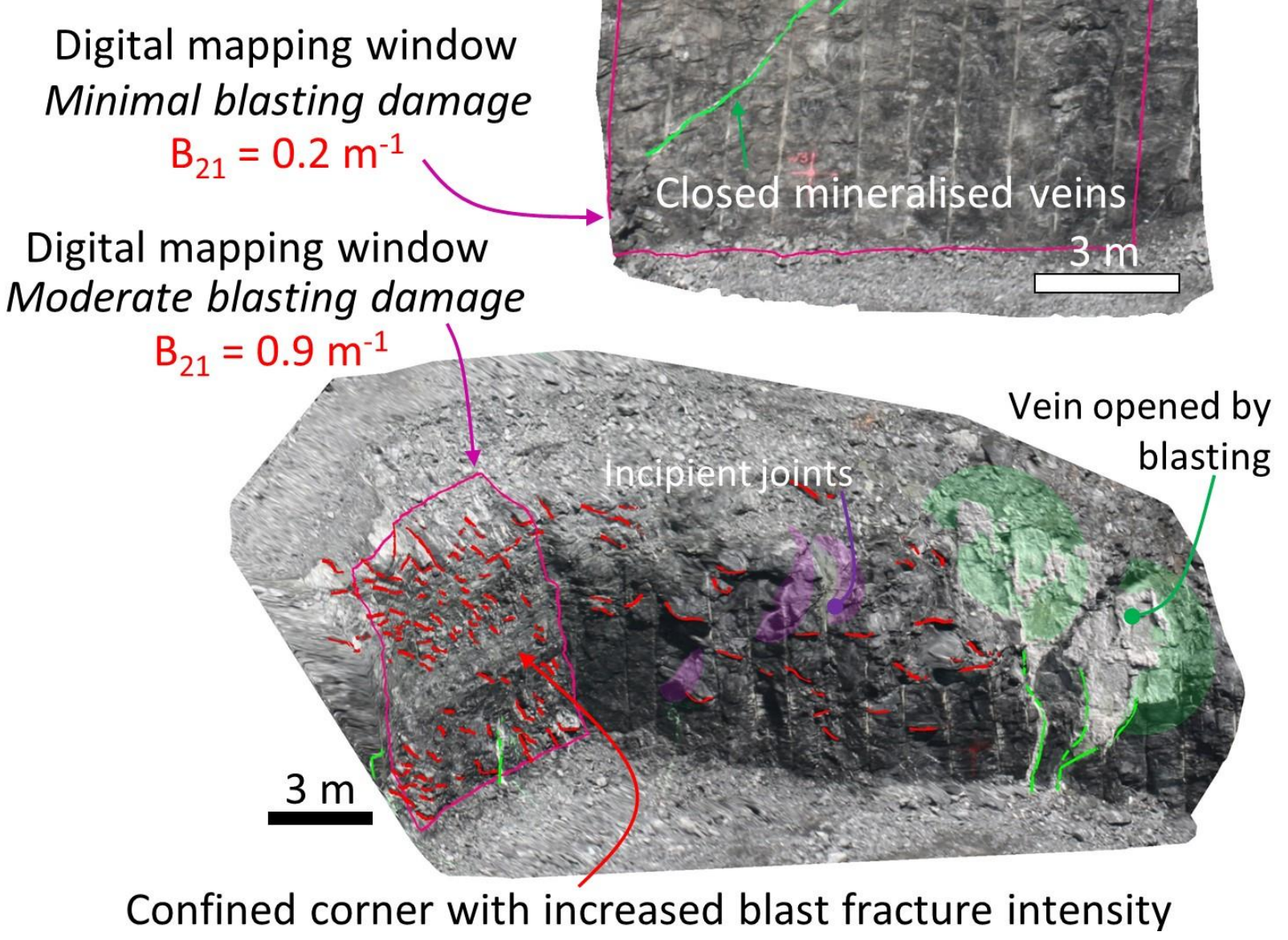

Figure 3 Blasting damage recorded in $\mathrm{f}=100 \mathrm{~mm}$ photogrammetry survey

We expect that most of the irregular brittle blast fractures are shallow, and do not extend far behind the slope face; however, we suggest that the areal intensity of blasting fractures expressed using the $\mathrm{B}_{21}$ parameter may provide a useful starting point for quantitative comparison of the local severity of brittle blasting damage in different bench faces. 


\section{$3 \quad$ Field investigation of an Australian open pit}

\subsection{Survey setup}

For the photogrammetry investigations, we spaced camera stations along the pit crest, and also took photographs from several locations along the main haul ramp and the base of the pit using lens focal length of $f=18 \mathrm{~mm}$ for global reconnaissance, and longer focal lengths of $f=28 \mathrm{~mm}, 55 \mathrm{~mm}$, and $100 \mathrm{~mm}$ to generate digital terrain models (DTM) for detailed discontinuity survey. The typical distance from the camera station to the slope was about $300 \mathrm{~m}$. Ground pixel size (resolution) of the models varies from about $7 \mathrm{~cm}$ for DTMs constructed using $f=28 \mathrm{~mm}$ photographed from the pit crest, to about $2 \mathrm{~cm}$ for $f=100 \mathrm{~mm}$ models.

Figure 4 illustrates the linear relationship between ground pixel size and camera distance to the slope, with a secondary vertical axis delineating our suggested practical truncation length for discontinuity mapping; features smaller than the truncation length are ignored. We achieved a truncation length of about $250 \mathrm{~mm}$ in DTMs constructed from long-range $f=100 \mathrm{~mm}$ photographs. However, the peak frequency in the mapping dataset occurs for discontinuities with fitted disc diameter between 1 and $2 \mathrm{~m}$, reflecting scale bias: we focused first on the most persistent discontinuities, and then mapped progressively smaller structures until further mapping became impractical due to time constraints, model resolution, and project scope.
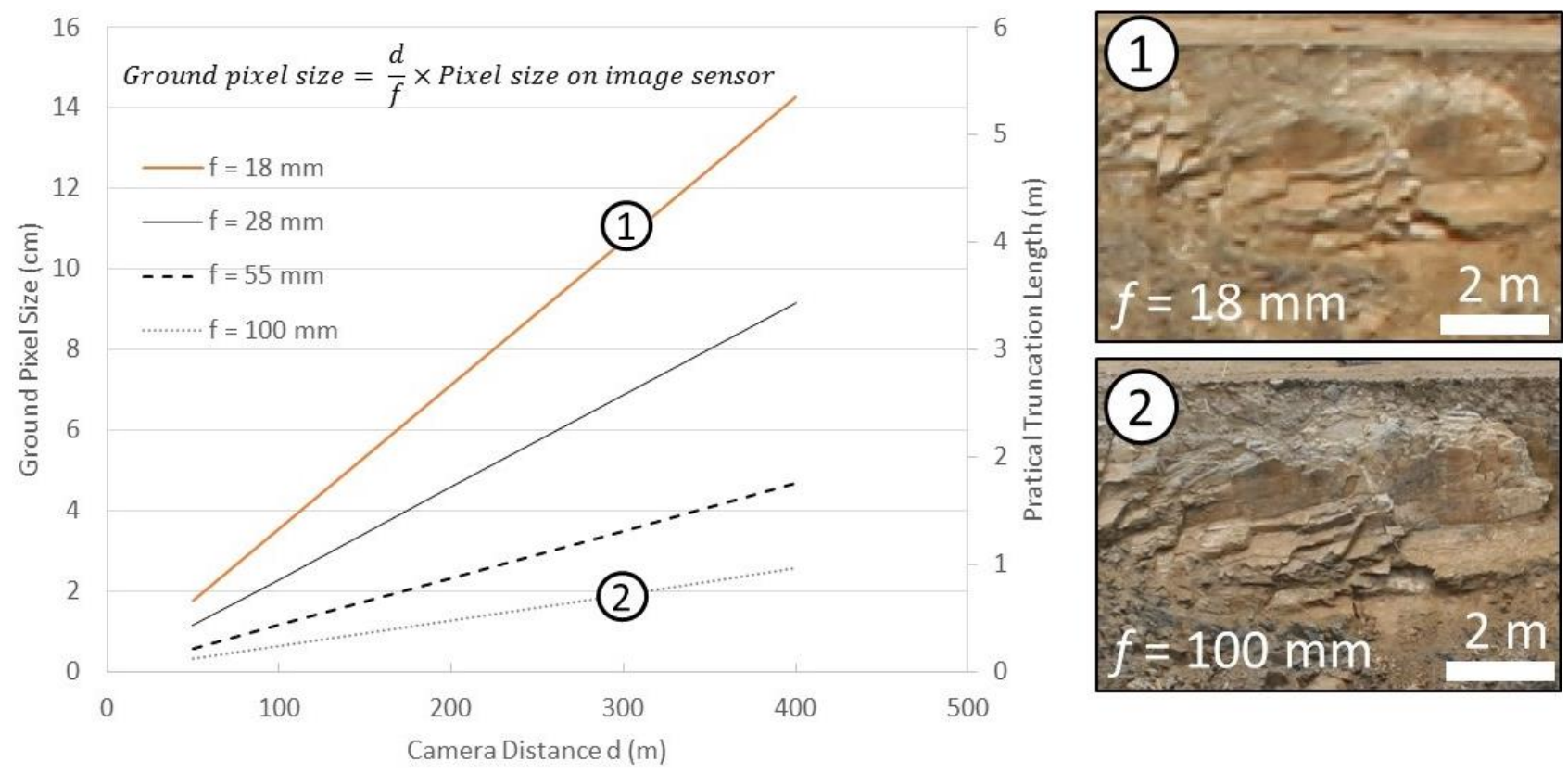

Figure 4 Typical variation in ground pixel size and practical truncation length for a Canon EOS 30D

\subsection{Discontinuity mapping results}

Figure 5 shows normalised frequency of fitted discontinuity diameter for the combined dataset, along with distributions for eight arbitrary orientation ranges: A1 to A4 are steep to moderately dipping discontinuities; sets B1 to B4 comprise moderately dipping to horizontal discontinuities. The histograms illustrate how the data can be used to characterise persistence for different joint sets with respect to the ISRM (1978) recommended categories, ranging from very low (VL) to very high (VH). For anonymity, the dataset includes measurements from all different geotechnical domains around the pit; we emphasise that the structural trends are not representative of geotechnical conditions in any one geotechnical domain. 

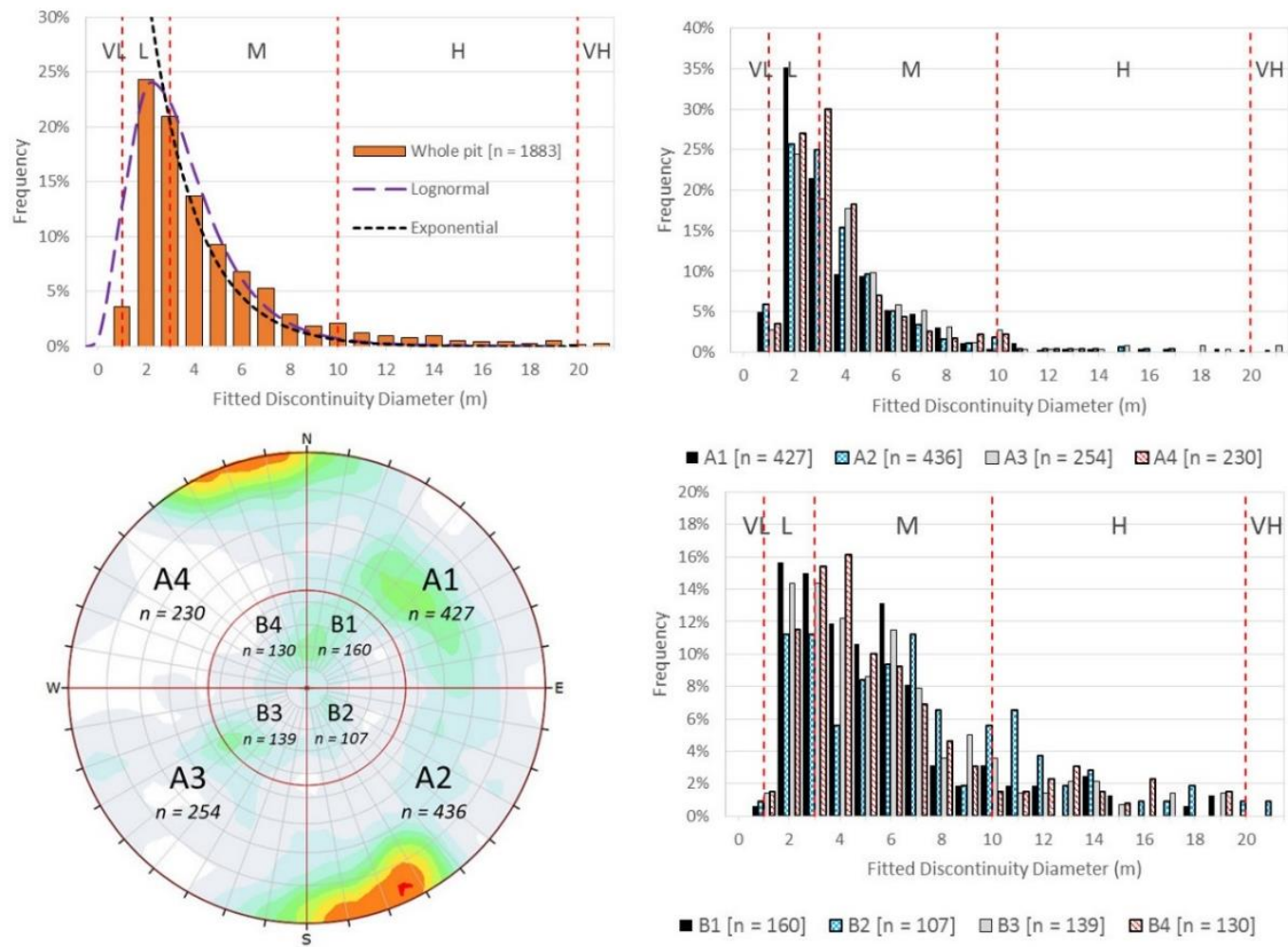

Figure 5 Normalised frequency of discontinuity diameter from photogrammetry dataset $(n=1883)$

The data seems well fitted to a lognormal distribution for trace lengths up to $20 \mathrm{~m}$, which captures the reduction in frequency for low persistence joints with diameter less than one metre, approaching the truncation limit. Alternatively, a negative exponential distribution can be used to reflect the real world expectation of exponentially increasing frequency of discontinuities with reducing size, approaching infinity as persistence reduces towards the scale of microcracks.

When the discontinuity diameter data are plotted on logarithmic axes, more than one relationship can be discerned (Figure 6). One lognormal relationship provides a good lower-bound fit for minor and intermediate scale structures, with persistence less than about $20 \mathrm{~m}$. However, between persistence of 10 and $20 \mathrm{~m}$, the data become more scattered, and we have indicated an upper-bound lognormal function to capture the frequency of major structures with very high persistence.

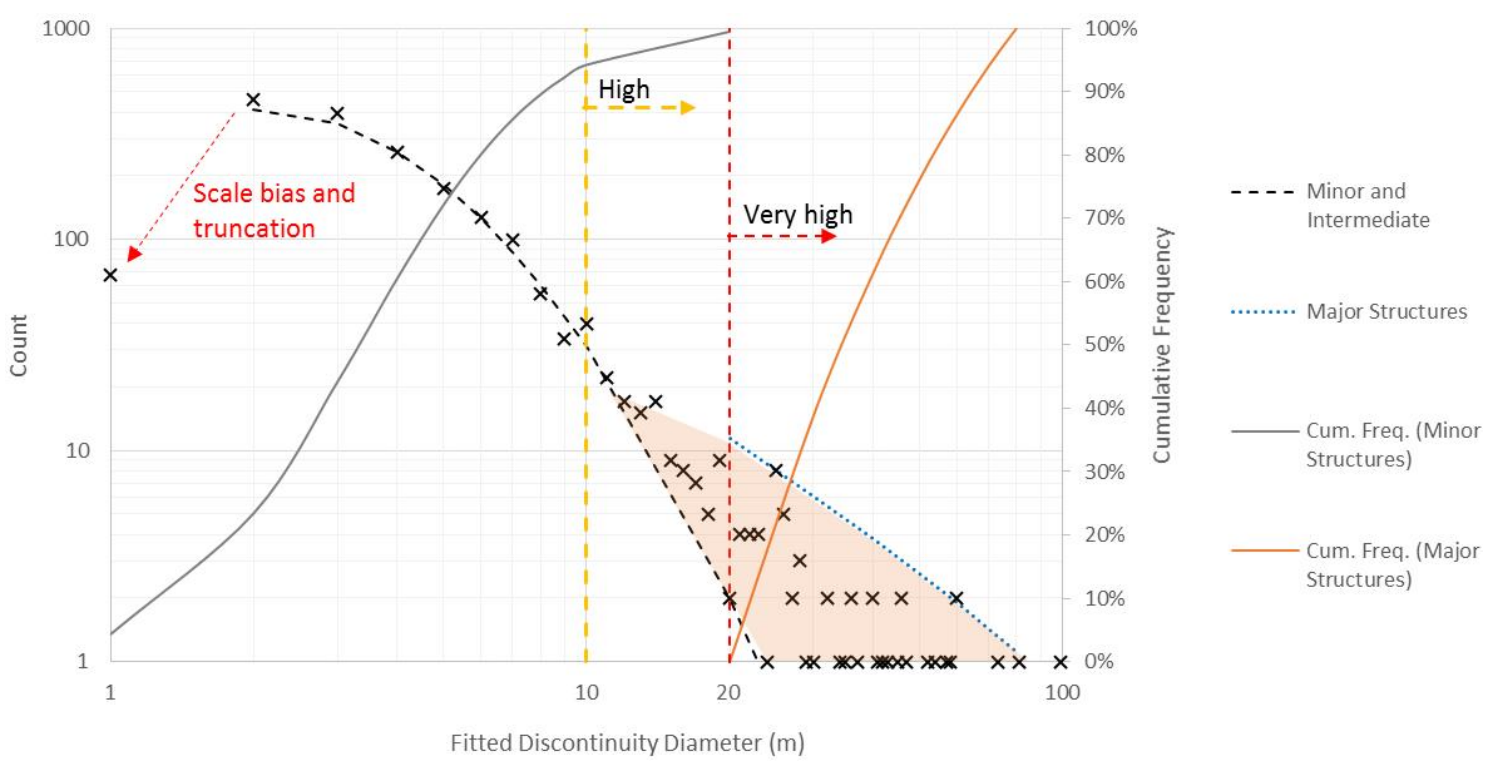

Figure 6 Logarithmic scale plot of fitted discontinuity diameters including minor and major structures 
About $15 \%$ of the total population fall into the 'very high' persistence category, but we suggest that these structures may be treated as a distinct population for assessment of inter-ramp or overall slope scale instability mechanisms controlled by major structures. Characterisation of the most persistent discontinuities intersecting an open pit slope is already part of conventional mapping approaches (Lorig et al. 2009). However, we suggest that analysis of a large dataset of discontinuity trace lengths or diameters mapped using photogrammetry can help to improve confidence in field estimates of persistence, and can be used to derive detailed persistence-frequency relationships for use in DFN simulations.

Once the most persistent discontinuities relevant to slope stability are identified, targeted detailed photogrammetry mapping of each major discontinuity can help to characterise surface morphology. Understanding the waviness (first order roughness) of major discontinuities is particularly important for shear strength estimation in multi-bench, inter-ramp, or overall slopes scale stability analysis. The 3D models produced from photogrammetry provide excellent opportunity to assess waviness of very persistent undulating discontinuities. We suggest that large scale undulating discontinuities can be more fully described using polylines to measure trace length, apparent amplitude and apparent wavelength, and regularly spaced planar discs fitted along the strike length of the discontinuity to characterise the variation in local orientation for derivation of waviness angle, for example by using a Fisher $K$ constant (Figure 7).

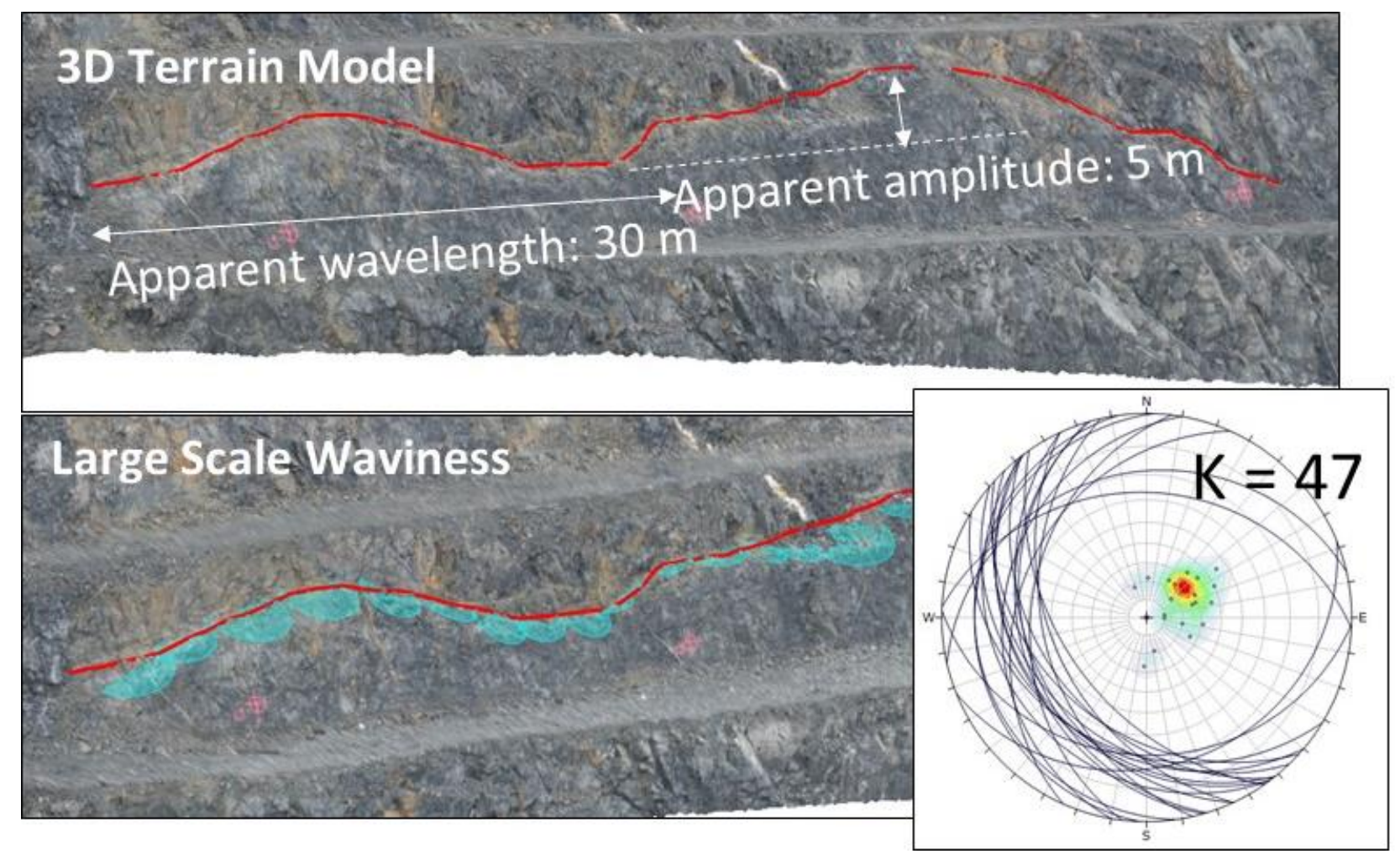

Figure 7 Waviness of a very high persistence, undulating discontinuity

\subsection{Window mapping and intact rock bridges}

We carried out targeted bench scale photogrammetry window mapping in order to investigate trends in discontinuity persistence and fracture intensity, and to conceptually investigate the role of intact rock bridges separating discontinuity tips. Figure 8 shows one example window, approximately $36.6 \mathrm{~m}$ wide and $12.8 \mathrm{~m}$ high, with an idealised flat surface area of $468 \mathrm{~m}^{2}$ and 3D triangulated surface area of $550 \mathrm{~m}^{2}$. 


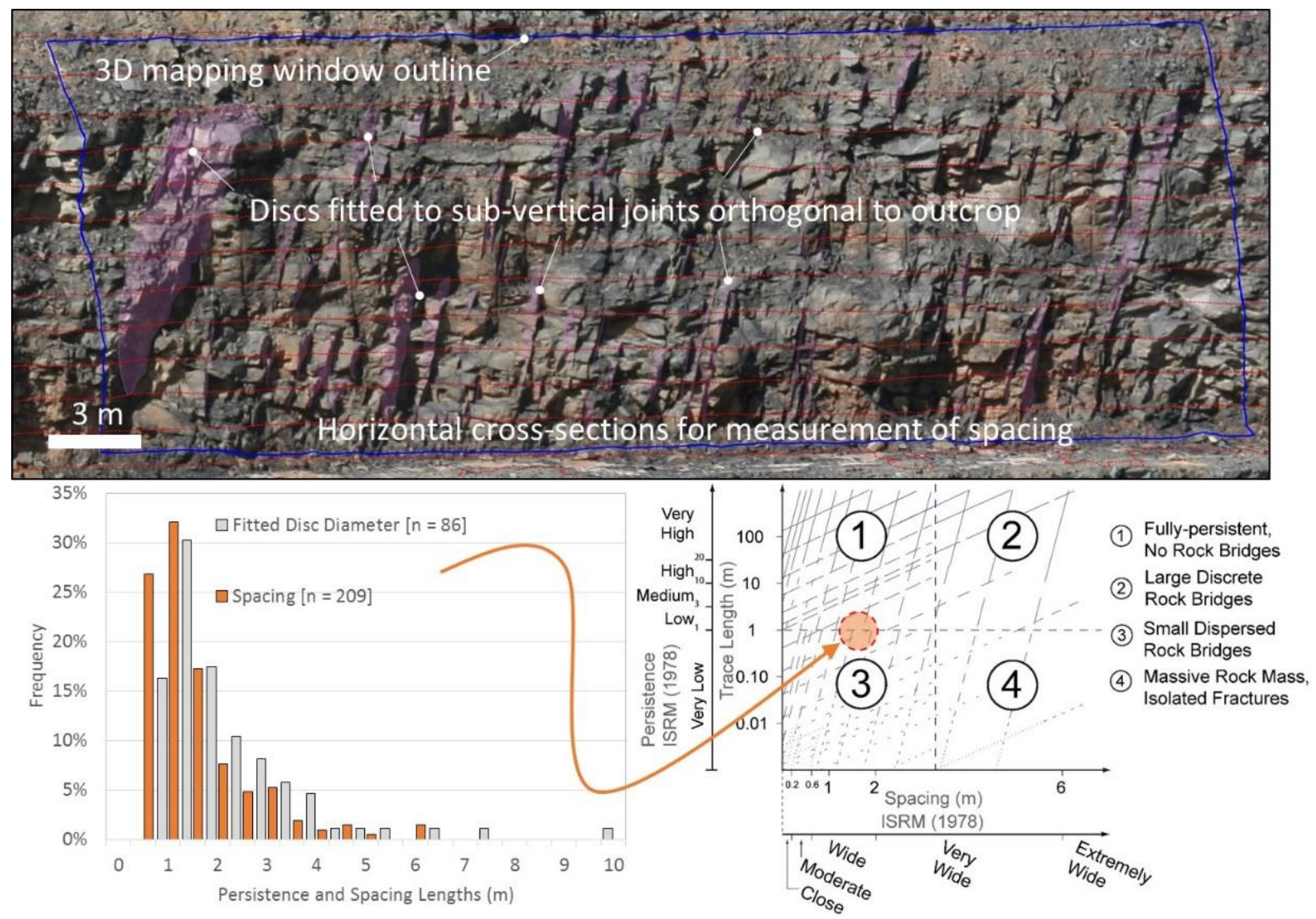

Figure 8 Digital bench face map with good conditions for measurement of spacing and persistence

For this example we focus on one major joint set, locally steeply dipping and striking approximately orthogonal to the bench face. The joint set orientation provides ideal conditions for measuring discontinuity spacing. In total we mapped 86 joint segments intersecting the window, and took 209 spacing measurements between them, along horizontal scanlines spaced at $1 \mathrm{~m}$ intervals. The intensity of pre-existing fractures $\left(\mathrm{P}_{21}\right)$ is $0.38 \mathrm{~m}^{-1}$ if discontinuity trace lengths are evaluated against an idealised $2 \mathrm{D}$ window, or $0.32 \mathrm{~m}^{-1}$ if they are evaluated against the 3D triangulated surface area of the window.

The peak frequency for open joint plane diameter (apparent persistence) is between one and two metres, however the sub-vertical fabric appears persistent, and inferred joint traces could be interpreted to extend the full height of bench, with rock bridges separating the tips of joints terminating in intact rock.

Figure 8 also includes a conceptual diagram relating discontinuity spacing and persistence according the ISRM guidelines, with four suggested domains for describing the content of intact rock bridges in a layered rock mass. With peak frequency of discontinuity spacing and persistence both typically in the range of one to two metres, this rock mass could be qualitatively characterised as transitionary between conceptual domains 1 and 3 . The sub-vertical joints are not fully persistent over the full bench height, and open discontinuity segments may be separated by zones of incipient microcracking or intact rock bridges with dimensions in the approximate range of 100 to $500 \mathrm{~mm}$.

\subsection{Bench performance and blasting damage}

Pre-existing discontinuities can reflect the dynamic compression waves induced during blasting and limit the extent of blasting damage. In at least one instance we recorded zones of blasting-induced bench crest failure, bounded by a high persistence pre-existing discontinuity striking sub-parallel to the bench face (Figure 9). The photogrammetry models allowed us to measure the volume of blast-induced bench scale failures, and also to rapidly produce $2 \mathrm{D}$ cross sections for simplified limit equilibrium slope models, and for comparison of as-built versus design bench face angles and distribution of crest loss throughout the pit. 


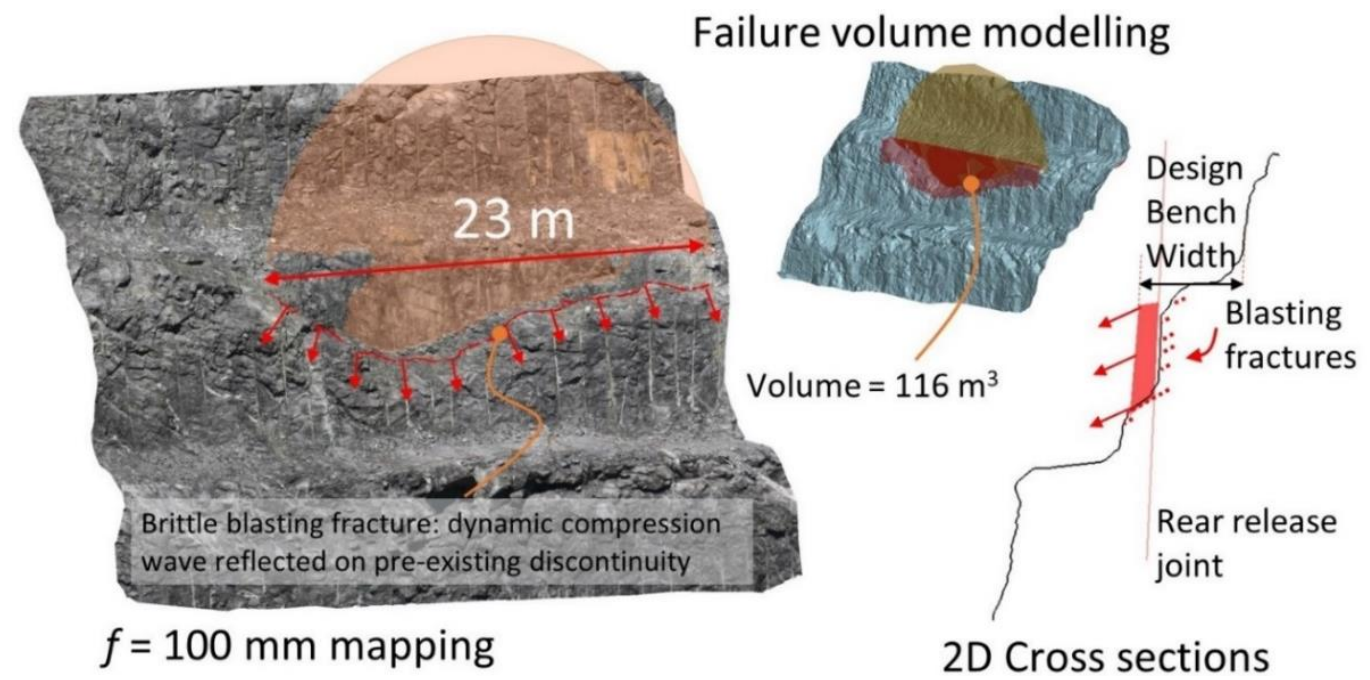

Figure 9 Interaction between pre-existing discontinuities and blasting induced damage

We suggest that photogrammetry mapping should employ a combined approach to characterising blast-induced damage, including: (1) window mapping of irregular blast fracture traces to derive the intensity parameter $\mathrm{B}_{21}$ and measure the severity of blast induced brittle fractures (Section 2.3); (2) discrete identification of significant blast-induced bench scale failures; and (3) systematic assessment of as-built bench face angles and crest widths using 2D cross sections derived from photogrammetry.

\section{$4 \quad$ Integrating photogrammetry and numerical modelling}

We carried out a conceptual finite element numerical modelling trial using Phase ${ }^{2}$ (Rocscience 2015), with a simple DFN based on photogrammetry mapping results, but not explicitly indicative of the expected rock mass fabric at any particular location (Figure 10). We selected artificial Mohr-Coulomb shear strength parameters corresponding to a moderately strong jointed rock mass (Franz 2009; Hammah et al. 2008), but not representative of the overall rock mass design parameters used at this mine.

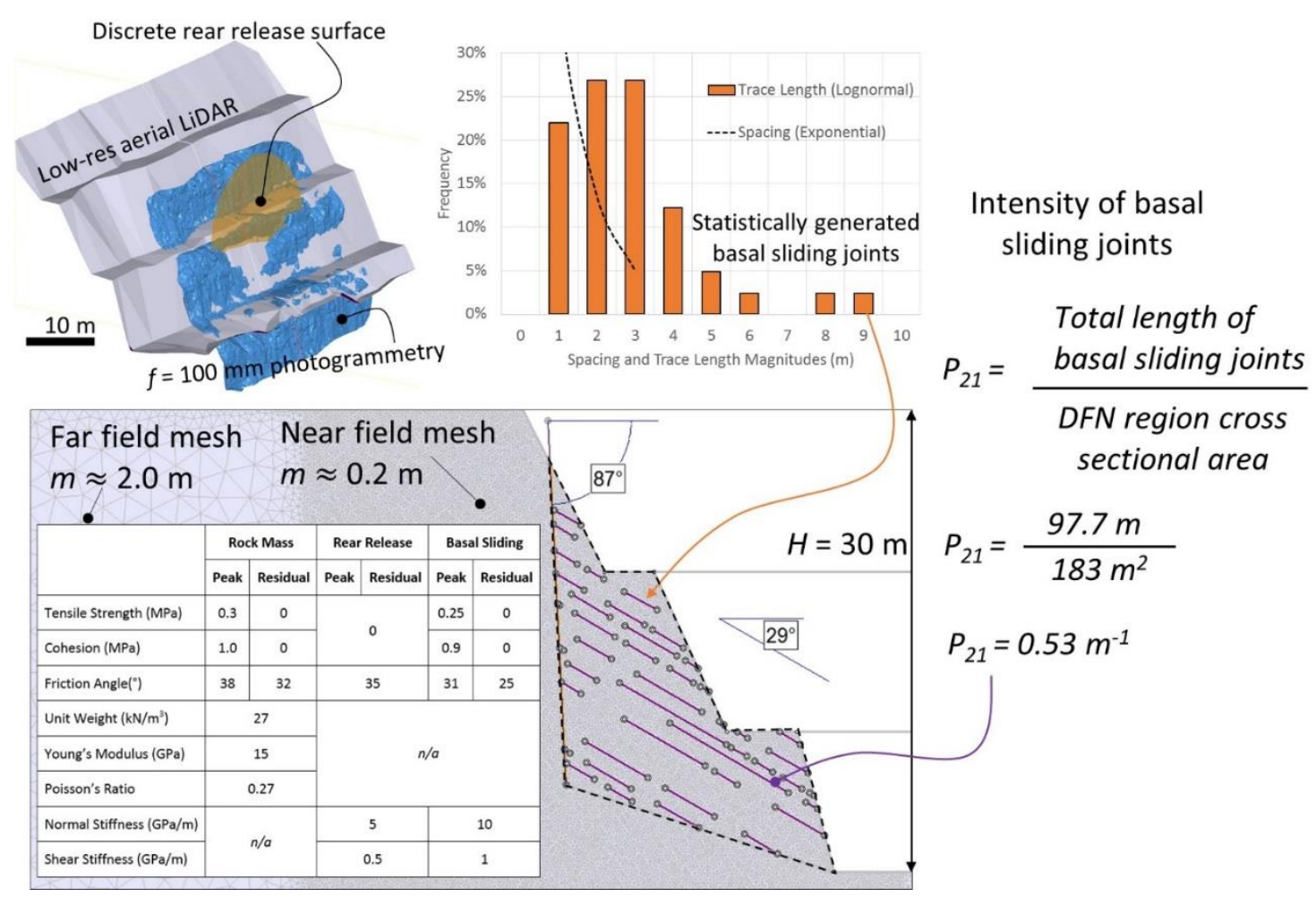

Figure 10 Conceptual FEM setup for bench scale simulation of bi-planar slope instability 
The model simulates an approximately bi-planar step-path failure, with a discrete, steeply dipping rear release joint with very high persistence, and statistically generated basal sliding joints with mostly low to medium persistence and spacing between 1 and $3 \mathrm{~m}$. Joint termination conditions are open, which allows for some limited differential displacements to occur along the joint elements.

In the first three simulation stages the benches are excavated. Next, the cohesion and tensile strength of basal sliding discontinuities are progressively reduced, while all other parameters are held constant, including the discontinuity friction angles. The reduction in cohesion and tensile strength of the basal sliding joints is intended to investigate the role of rock bridge degradation along the basal sliding joints: brittle fracture of the intact rock bridges must occur before shear displacement and frictional strength mobilisation.

The results show that global instability (indicated by non-convergence of the implicit force balance solution process) occurs when the cohesion and tensile strength of the basal sliding joints are reduced to below about $7 \%$ of their original values, or cohesion of $63 \mathrm{kPa}$ and tensile strength of $18 \mathrm{kPa}$ (Figure 11). Even under stable conditions, some preliminary yielding of the rear release surface occurs, along with fracture propagation from the tips of some basal sliding joints, and incipient rock bridge failure near the toe of the slope.
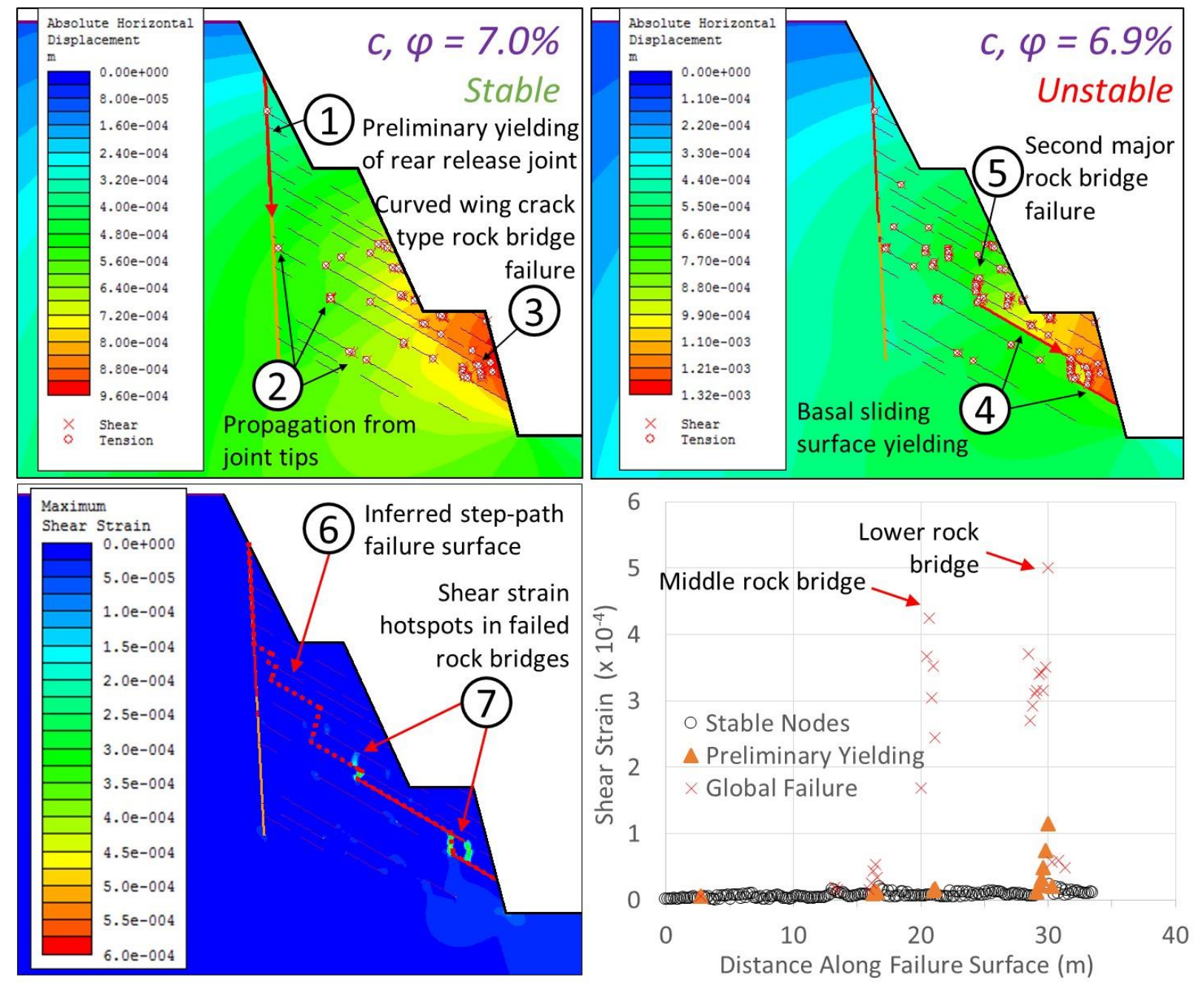

Figure 11 Conceptual FEM results highlighting progressive step-path failure development

When the cohesion and tensile strength of the basal joints are reduced below $7 \%$ of their original values, the incipient rock bridge failure near the toe of the slope propagates to form a continuous step-path, and a second major rock bridge failure occurs in the middle of the slope. Because Phase ${ }^{2}$ is limited to small displacements occurring just at the onset of global instability, the shear strain along most of the inferred step-path failure surface is generally small $\left(<<1 \times 10^{-4}\right)$; however, locally elevated shear strain hotspots $\left(5 \times 10^{-4}\right)$ correspond to the two major rock bridge failures. 
We also carried out a shear strength reduction (SSR) analysis, which solves for a critical strength reduction factor (SRF), a proxy for Factor of Safety that describes the shear strength reduction required to induce instability. For this model the results show a very high SRF value of 7.9, suggesting high confidence in the stability of a slope with these input parameters. However, the SSR routine does not degrade cohesion and tensile strength before mobilising friction: the routine automatically reduces discontinuity friction angles, along with cohesion and tensile strength; consequently, a different instability mechanism occurs. Instead of a multi-bench step-path failure, the instability is confined to the lower bench, where steeply dipping rock mass fractures propagate and form rear release surfaces for a bench scale step-path failure (Figure 12).

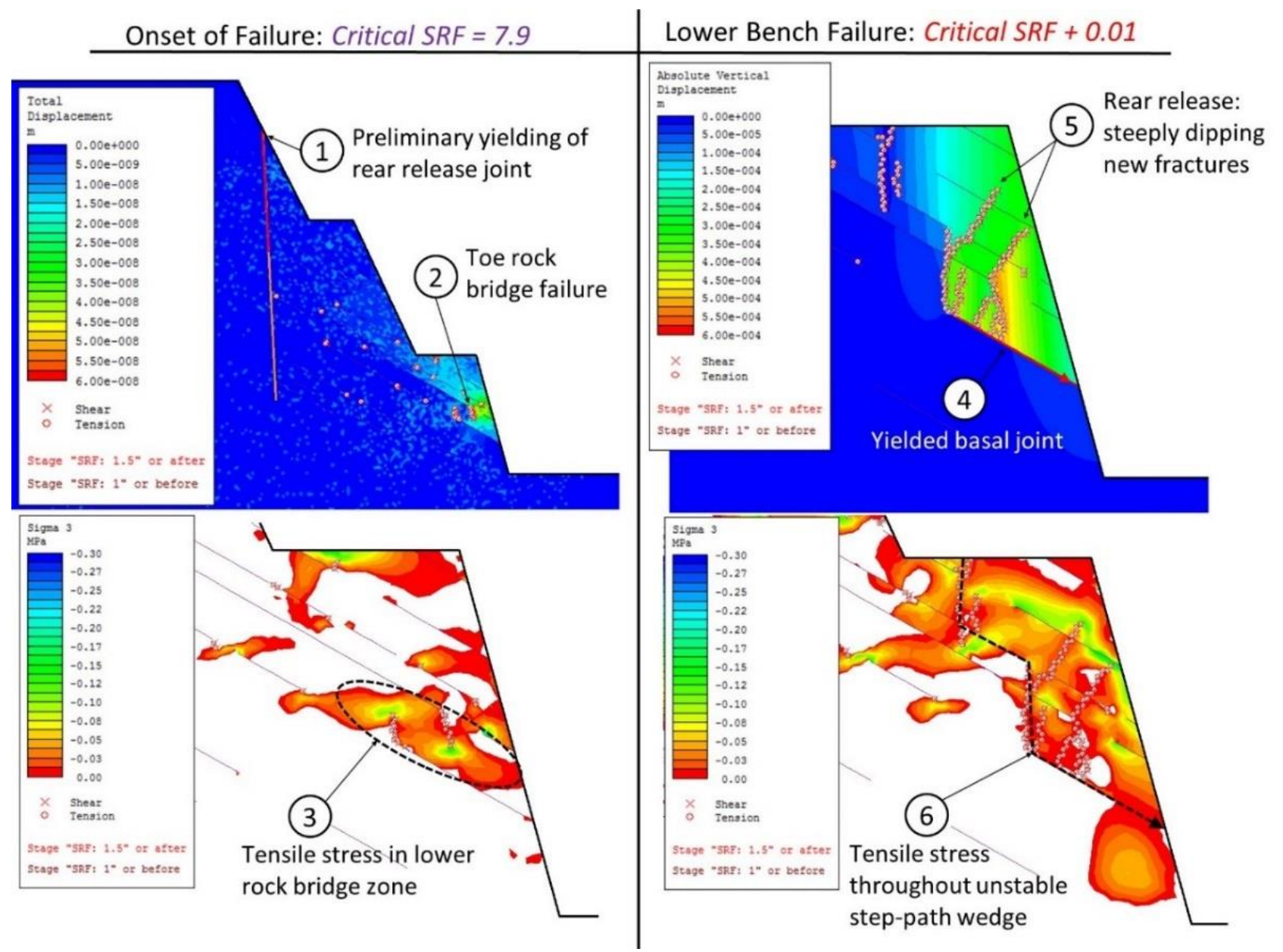

Figure 12 Alternative failure mechanism resulting from SSR analysis

Because the SSR analysis simultaneously reduces cohesion and friction angle, we suggest that it is not well suited to simulating the progressive deterioration of cohesion and tensile strength that occurs along incipient discontinuities specifically before frictional strength is mobilised. In this case, the SSR analysis predicts a critical failure mechanism characterised by step-path instability confined to the lower bench. The result could be non-conservative when compared against the multi-bench step-failure that occurs in the base case simulation, where only cohesion and tensile strength are reduced before failure.

We emphasise that this simulation represents only one stochastic realisation of the basal sliding joint network. A probabilistic approach to slope stability evaluation would require evaluation of multiple possible DFN realisations in order to characterise the range of possible discontinuity geometries.

\section{Conclusion}

Despite its increasing use in open pit slope design, we suggest that there is abundant scope to improve procedures for rock discontinuity mapping using photogrammetry. We propose that a combined approach 
can help to more comprehensively characterise brittle blasting induced fractures and discontinuities with irregular morphology. In particular, the conventional approach to discontinuity mapping focussing on fitted circular discs can be supplemented with intensity measurements collected using 3D polylines, and 3D measurements of apparent amplitude and wavelength for very high persistence discontinuities.

Statistical information on joint spacing and trace length, gathered using photogrammetry, can readily be incorporated into finite element models using DFN tools. However, we urge care in the application of shear strength reduction techniques, noting that different results can be obtained depending on whether models consider cohesion and tensile strength degradation to occur before shear displacement and mobilisation of frictional strength.

\section{Acknowledgement}

We thank the mine owner for permission to publish.

\section{References}

Almeida, LCR, Vargas Jr, E.do A \& de Figueiredo, RP 2006, 'Mechanical characterization of rock splitting planes in granitic rocks', International Journal of Rock Mechanics and Mining Sciences, vol. 43, pp. 1139-1145.

Alzo'ubi, AM 2009, 'The effect of tensile strength on the stability of rock slopes', PhD thesis, University of Alberta.

Ameen, MS 1995, Fractography: fracture topography as a tool in fracture mechanics and stress analysis, Geological Society, Special publication, London, no. 92, pp. 1-10.

Baecher, GB \& Lanney, NA 1978, 'Trace Length Biases in Joint Surveys', in Proceedings of the 19th US Symposium on Rock Mechanics (USRMS), Reno, Nevada, vol. 1, pp. 56-65.

Bahat, D, Rabinovitch, A \& Frid, V 2005, Tensile Fracturing in Rocks: Tectonofractographic and Electromagnetic Radiation Methods, Springer, Berlin, p. 569.

Bjerrum, L 1967, 'Progressive failure in slopes of overconsolidated plastic clay and clay shales', Journal of the Soil Mechanics and Foundation Division, ASCE, vol. 93, SM5, pp. 1-49.

Brideau, MA, Yan, M \& Stead, D 2009, 'The role of tectonic damage and brittle rock fracture in the development of large rock slope failures', Geomorphology, vol. 103, pp. 30-49.

Eberhardt, E 1998, 'Brittle Rock Fracture and Progressive Damage in Uniaxial Compression', PhD dissertation, University of Saskatchewan.

Elmo, D, Liu, Y \& Rogers, S 2014, 'Principals of discrete fracture network modelling for geotechnical applications', in D Kennard, D Stead, E Eberhardt \& D Elmo (eds), in Proceedings of the First International Conference on Discrete Fracture Network Engineering, Vancouver.

Etchells, SJ, Sellers, EJ \& Furtney, J 2013, 'Understanding the blast damage mechanisms in slopes using observations and numerical modelling', in PM Dight (ed.), Proceedings of the International Symposium on Slope Stability in Open Pit Mining and Civil Engineering, Australian Centre for Geomechanics, Perth, pp. 1359-1372.

Fekete, S, Diederichs, M \& Lato, M 2010, 'Geotechnical and operational applications for 3-dimensional laser scanning in drill and blast tunnels', Tunnelling and Underground Space Technology, vol. 25, pp. 614-628.

Franz, J 2009, 'An investigation of combined failure mechanisms in large scale open pit slopes', PhD thesis, University of New South Wales.

Gudmundsson, A 2011, Rock Fractures in Geological Processes, Cambridge University Press, New York, p. 591.

Hadjigeorgiou, J, Lemy, F, Cote, P \& Maldague, X 2003, 'An evaluation of image algorithms for constructing discontinuity trace maps', Rock Mechanics and Rock Engineering, vol. 36(2), pp. 163-179.

Hagan, TN, McIntyre, JS \& Boyd, GL 1978, 'The influence of blasting in mine stability', in CO Brawner \& IP Dorling (eds), Proceedings of the 1st International Symposium on Coal Mine Stability, Vancouver, pp. 95-122.

Hammah, RE, Yacoub, T, Corkum, B \& Curran, JH 2008, 'The practical modelling of discontinuous rock masses with finite element analysis', in Proceedings of the 42nd U.S. Rock Mechanics Symposium, San Fransciso, p. 8.

Hencher, S 2014, 'Characterising discontinuities in naturally fractured outcrop analogues and rock core: The need to consider fracture development over geological time', Geological Society Special Publication, vol. 374, pp. 113-123.

Hencher, S 2015, Practical Rock Mechanics, CRC Press, Taylor and Francis Group, p. 378.

Hencher, SR \& Knipe, R 2007, 'Development of rock joints with time and consequences for engineering', in L Ribeiro e Sousa, C Olalla \& N Grossman (eds.), Proceedings of the 11th Congress of the International Society for Rock Mechanics, Lisbon, vol. 1, pp. 223-226.

Hoek, E \& Karzulovic, A 2000, 'Rock mass properties for surface mines', in WA Hustralid, MK McCarter \& DJA van Zyl (eds), Slope Stability in Surface Mining, Littleton, Colorado, Society for Mining, Metallurgical and Exploration (SME), pp. 59-70.

ISRM (International Society for Rock Mechanics) 1978, 'Commission on standardization of laboratory and field tests: Suggested methods for the quantitative description of discontinuities in rock masses', International Journal of Rock Mechanics and Mining Sciences \& Geomechanics Abstracts, vol. 15(6), pp. 319-368.

Lato, M \& Vöge, M 2012, 'Automated mapping of rock discontinuities in 3D lidar and photogrammetry models', International Journal of Rock Mechanics \& Mining Sciences, vol. 54, pp. 150-158. 
Lato, M, Diederichs, M, Hutchinson, J \& Harrap, R 2009, 'Optimization of LiDAR scanning and processing for automated structural evaluation of discontinuities in rockmasses', International Journal of Rock Mechanics \& Mining Sciences, vol. 46, pp. $194-199$.

Lato, M, Diederichs, M, Hutchinson, J \& Harrap, R 2012, 'Evaluating roadside rockmasses for rockfall hazards using LiDAR data: optimising data collection and processing protocols', Natural Hazards, vol. 60, pp. 831-864.

Lemy, F \& Hadjigeorgiou, J 2003, 'Discontinuity trace map construction using photographs of rock exposures', International Journal of Rock Mechanics \& Mining Sciences, vol. 40, pp. 903-917.

Lorig, L, Stacey, P \& Read, J 2009, 'Slope Design Methods', in J Read \& P Stacey (eds), Guidelines for open pit slope design, CSIRO Publishing, Collingwood, Victoria, p. 510.

Mandl, G 2005, Rock Joints: The Mechanical Genesis, Springer, p. 222.

Mas Ivars, D, Pierce, ME, Darcel, C, Reyes-Montes, J, Potyondy, DO, Young, RP \& Cundall, P 2011, 'The synthetic rock mass approach for jointed rock mass modelling', International Journal of Rock Mechanics \& Mining Sciences, vol. 48, pp. 219-244.

Ortega, O, Marrett, RA \& Laubach, S 2006, 'A scale-independent approach to fracture intensity and average spacing measurement', AAPG Bulletin, vol. 90(2), pp. 193-208.

Patton, FD 1966, 'Multiple modes of shear failure in rock', in Proceeding of the 1st Congress of International Society of Rock Mechanics, Lisbon, vol. 1, pp. 509-513.

Priest, SD 1993, Discontinuity Analysis for Rock Engineering, Chapman \& Hall, London, p. 473.

Rocscience 2015, Phase2 version 8.024 64-bit, build date March 4, 2015.

Shang, J, Hencher, SR \& West, LJ 2015, 'Tensile strength of incipient rock discontinuities', in W Schubert \& A Kluckner (eds), Proceedings of the SRM Regional Symposium EUROCK 2015 \& 64th Geomechanics Colloquium, Salzburg.

Stead, D \& Eberhardt, E 2013, 'Understanding the mechanics of large landslides', in International Conference on Vajont, Padova, Italy, Italian Journal of Engineering Geology and Environment - Book Series (6), pp. 85-112.

Stead, D \& Wolter, A 2015, 'A critical review of rock slope failure mechanisms: the importance of structural geology', Journal of Structural Geology, vol. 74, pp. 1-23.

Sturzenegger, M \& Stead, D 2009, 'Close-range terrestrial digital photogrammetry and terrestrial laser scanning for discontinuity characterization on rock cuts', Engineering Geology, vol. 106, pp. 163-182.

Terzaghi, RD 1965, 'Sources of error in joint surveys', Geotechnique, vol. 15, pp. 287-304.

Wolter, A 2014, 'Characterisation of Large Catastrophic Landslides using an Integrated Field, Remote Sensing, and Numerical Modelling Approach', PhD thesis, Simon Fraser University.

Wolter, A, Stead, D \& Clague, J 2014, 'A morphologic characterisation of the 1963 Vajont Slide, Italy, using long-range terrestrial photogrammetry', Geomorphology, vol. 206, pp. 147-167.

Ziegler, M 2014, 'Age and formation mechanisms of exfoliation joints in the Aar Granites of the central Alps (Grimsel region, Switzerland)', PhD dissertation, ETH Zurich. 